\title{
Parkinson's Disease-Associated LRRK2 Hyperactive Kinase Mutant Disrupts Synaptic Vesicle Trafficking in Ventral Midbrain Neurons
}

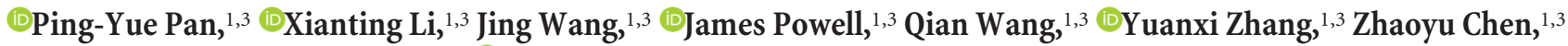 \\ Bridget Wicinski, ${ }^{2,3}$ Patrick Hof, ${ }^{2,3}$ DTimothy A. Ryan, ${ }^{4}$ and Zhenyu Yue ${ }^{1,3}$ \\ ${ }^{1}$ Department of Neurology, ${ }^{2}$ Department of Neuroscience, and ${ }^{3}$ Friedman Brain Institute, Icahn School of Medicine at Mount Sinai, New York, New York \\ 10029, and ${ }^{4}$ Biochemistry Department, Weill Cornell Medical College, New York, New York 10029
}

Parkinson's disease (PD) is characterized pathologically by the selective loss of substantia nigra (SN) dopaminergic (DAergic) neurons. Recent evidence has suggested a role of LRRK2, linked to the most frequent familial PD, in regulating synaptic vesicle (SV) trafficking. However, the mechanism whereby LRRK2 mutants contribute to nigral vulnerability remains unclear. Here we show that the most common PD mutation LRRK2 G2019S impairs SV endocytosis in ventral midbrain (MB) neurons, including DA neurons, and the slowed endocytosis can be rescued by inhibition of LRRK2 kinase activity. A similar endocytic defect, however, was not observed in LRRK2 mutant neurons from the neocortex (hereafter, cortical neurons) or the hippocampus, suggesting a brain region-specific vulnerability to the G2019S mutation. Additionally, we found MB-specific impairment of SV endocytosis in neurons carrying heterozygous deletion of SYNJ1 (PARK20), a gene that is associated with recessive Parkinsonism. Combining SYNJ1 ${ }^{+/-}$and LRRK2 G2019S does not exacerbate SV endocytosis but impairs sustained exocytosis in MB neurons and alters specific motor functions of 1-year-old male mice. Interestingly, we show that LRRK2 directly phosphorylates synaptojanin1 in vitro, resulting in the disruption of endophilin-synaptojanin1 interaction required for SV endocytosis. Our work suggests a merge of LRRK2 and SYNJ1 pathogenic pathways in deregulating SV trafficking in MB neurons as an underlying molecular mechanism of early PD pathogenesis.

Key words: dopamine neuron; genetic interaction; LRRK2 G2019S; Parkinson's disease; synaptic vesicle; synaptojanin1/synj1

Significance Statement

Understanding midbrain dopaminergic (DAergic) neuron-selective vulnerability in PD is essential for the development of targeted therapeutics. We report, for the first time, a nerve terminal impairment in SV trafficking selectively in MB neurons but not cortical neurons caused by two PARK genes: LRRK2 (PARK8) and SYNJ1 (PARK20). We demonstrate that the enhanced kinase activity resulting from the most frequent G2019S mutation in LRRK2 is the key to this impairment. We provide evidence suggesting that LRRK2 G2019S and SYNJ1 loss of function share a similar pathogenic pathway in deregulating DAergic neuron SV endocytosis and that they play additive roles in facilitating each other's pathogenic functions in PD.

\section{Introduction}

Parkinson's disease (PD) is the most common neurodegenerative movement disorder, and it is thought to occur due to substantial

Received April 12, 2017; revised 0ct. 9, 2017; accepted 0ct. 11, 2017.

Author contributions:P.-Y.P., B.W.,P.H., T.A.R., and Z.Y. designed research;P.Y.P., X.L.,J.W., J.P., Q.W.,Y.Z., and Z.C. performed research; X.L. contributed unpublished reagents/analytic tools; P.-Y.P. and B.W. analyzed data; P.-Y.P., P.H., and Z.Y. wrote the paper.

The work was supported by Cote Early Investigator Award PD14-00011 to P.-Y.P., Parkinson's Disease Foundation International Research Grant PDF-IRG-1447 to Z.Y., National Institute of Neurological Disorders and Stroke R21 Grant 1R21NS095155-01 to P.-Y.P. and Z.Y., and National Institute of Neurological Disorders and Stroke R01 Grant R01NS060809 to Z.Y. and T.A.R. We thank Dr. Dongming Cai (Mount Sinai Veterans Administration campus) and Dr. Pietro De Camili (Yale University) for sharing SYNJ1 ${ }^{+/-}$mice; Dr. Rong Wang at (Mount Sinai Genomics Center) for performing mass spectrometry analysis; and Dr. Pietro De Camili (Yale University) for providing GFP-endoA and FLAG-GFP-synj1 constructs. loss of the nigral dopaminergic (DAergic) neurons in the ventral midbrain (MB). Human genetic studies have identified $>20$ genetic variants, which are linked to PD pathogenesis (Hardy et al., 2006; Hernandez et al., 2016); however, we have so far gained little insight in nigral DAergic neuron vulnerability based on these findings. Mutations in $L R R K 2 / P A R K 8$ represent the greatest contributor to inherited forms as well as some sporadic forms of PD (Paisán-Ruíz et al., 2004; Zimprich et al., 2004). The most

Correspondence should be addressed to Dr. Zhenyu Yue, Neurology Department, Icahn School of Medicine at Mount Sinai, One Gustave L. Levy Place, New York, New York 10029. E-mail: zhenyu.yue@mssm.edu. DOI:10.1523/JNEUROSCI.0964-17.2017

Copyright $\odot 2017$ the authors $\quad 0270-6474 / 17 / 3711366-11 \$ 15.00 / 0$ 
frequent Gly2019Ser (G2019S) mutation in LRRK2 kinase domain results in enhanced kinase activity (West et al., 2005), suggesting a gain-of-toxic-function as the potential pathogenic mechanism. Many pathogenic pathways of LRRK2 mutants were suggested; however, validation of the diseaserelated pathways is hindered by the lack of robust mammalian models of LRRK2 PD mutations (Yue and Lachenmayer, 2011). Thus, the molecular mechanism underlying the pathogenesis of LRRK2 mutant remains mostly elusive. Despite the lack of obvious PD-like toxicity in the available rodent models, a common functional alteration in those models is associated with DA transmission deficiency (Tong et al., 2009; Melrose et al., 2010; Beccano-Kelly et al., 2015). We previously reported altered DA release/uptake in BAC transgenic mice expressing LRRK2 G2019S but not in control BAC mice expressing WT LRRK2 (Li et al., 2010). There has been little understanding, however, on the molecular basis of deregulated DA transmission.

Emerging evidence suggested a role of LRRK2 in synaptic vesicle (SV) recycling, which is supported by its localization to the SV fraction (Piccoli et al., 2014) and its regulation of synaptic proteins, including rab5b (Shin et al., 2008), NSF, synapsin (Piccoli et al., 2014), and endophilin (Matta et al., 2012; Arranz et al., 2015). Examination of the proteome and phosphoproteome of flies expressing LRRK2-R1441C also implicated dysfunctional SV recycling as a potential LRRK2 pathogenic pathway (Islam et al., 2016). A recent human study reported genetic variability within DNM3 (encoding dynamin3), which is known to regulate SV endocytosis (Raimondi et al., 2011), as an age-of-onset modifier for LRRK2 G2019S carriers (Trinh et al., 2016), further highlighting the contribution of SV dysfunction to PD pathogenesis. Whether the deregulated SV function represents a core mechanism for the dysfunctional DAergic system in PD-risk genetic backgrounds requires further validation in the relevant cell type.

We and others reported a novel recessive missense mutation (R258Q) in SYNJ1 (chromosome 21q22) known as PARK20, which is associated with early-onset Parkinsonism (Krebs et al., 2013; Quadri et al., 2013; Olgiati et al., 2014). SYNJ1 encodes a synapseenriched inositol phosphatase, synaptojanin1 (synj1), which is essential for SV endocytosis and neural development (Cremona et al., 1999). Mice carrying the disease mutation recapitulated PD-like motor deficits and displayed impaired SV clathrin coat removal and loss of nigral DAergic innervation (Cao et al., 2017). Interestingly, the synj1 binding partner endophilinA was recently reported as a potential substrate of LRRK2 (Matta et al., 2012; Arranz et al., 2015), which raises a possibility for the interaction of LRRK2, endophilin, and synj1 in the same pathogenic pathway of PD. Herein we examined cultured neurons derived from the ventral $\mathrm{MB}$, which contains mostly DAergic and GABAergic interneurons from the SN and VTA. We show impaired SV endocytosis caused by LRRK2 G2019S mutation or SYNJ1 heterozygosity in $\mathrm{MB}$ neurons, but not in cortical or hippocampal neurons. We report evidence that LRRK2 PD mutation and SYNJ1 deficiency converges at the MB neuron nerve terminal for deregulation of DA signaling in PD.

\section{Experimental Procedures}

Animals, cell culture, and transfection. Mice were housed in the pathogenfree Center for Comparative Medicine at Icahn School of Medicine at Mount Sinai. Handling procedures were in accordance with National Institutes of Health guidelines and approved by the Mount Sinai Institutional Animal Care and Use Committee. LRRK2 BAC transgenic mice were described previously (Li et al., 2010). SYNJ1 ${ }^{+/-}$mice were gifts from Dongming Cai's laboratory at the Mount Sinai Veterans Administration Hospital Campus. MB cultures (Mani and Ryan, 2009; Pan and Ryan, 2012) and cortical cultures (Mani et al., 2007) were prepared as described previously. Ventral MB (containing both VTA and SN) or cortices were dissected from P0-P1 mice pups of either sex and digested using papain (Worthington, catalog \#LK003178) or trypsin (SigmaAldrich, catalog \#T1005) supplemented with DNase (Sigma-Aldrich, catalog \#D5025), respectively. MB neurons were then prepared according to our previously published protocol plated at a cell density of 199,000 cells $/ \mathrm{cm}^{2}$ and grown in the Neurobasal-A based medium supplemented with GDNF (10 ng/ml, EMD Millipore, catalog \#GF030). Cortical neurons, which were also prepared from P0-P1 mice pups of either sex, were plated at 142,000 cells $/ \mathrm{cm}^{2}$ and grown in the MEM-based medium supplemented with insulin $(24 \mu \mathrm{g} / \mathrm{ml}$, Sigma, catalog \#I6634) and transferrin $(0.1 \mathrm{mg} / \mathrm{ml}$, Calbiochem, catalog \#616420). Typically, four P0-P1 mouse brains are required for an MB culture. Calcium phosphate was used for transfection to achieve sparse expression and to ensure analysis of single neurons during the imaging experiments. Transfection was performed at DIV 3-5 for MB neurons and at DIV 5-6 for cortical neurons, after which the growth medium was replaced with a fresh medium supplemented with an antimitotic agent, ARA-C (SigmaAldrich, catalog \#C6645). P0-P1 Sprague Dawley rat pups were used to make rat $\mathrm{MB}$ and hippocampal cultures as described previously (Ariel and Ryan, 2010; Pan and Ryan, 2012).

Constructs and cloning. FLAG-mLRRK2 WT and FLAG-mLRRK2 G2019S were engineered by inserting mLRRK2 cDNAs into p3xFLAGCMV-7.1 (Sigma-Aldrich, catalog \#E4026) via restriction sites, NotI and XbaI. pEGFP-N3-endophilin1 and pEGFP-C1-FLAG- $h$ SYNJ1 were gifts from the De Camili laboratory (Yale University). Site-directed mutagenesis (QuikChange Lightning kit, Agilent, catalog \#210518) was used to generate synj1 mutant constructs: synj1 T1205A, synj1 T1205E, synj1 T1202A, synj1 D769A. The following primers were used to generate synj1 mutant constructs: synj1 T1205A_forward: 5' -AGCACCCAAAAGCCC TGGAGCAACAAGGAAAGATAATATAG-3' ${ }^{\prime}$ synj1 T1205A_reverse: 5' CTATATTATCTTTCCTTGTTGCTCCAGGGCTTTTGGGTGCT-3'; synj1 T1205E_forward: 5'-AGCACCCAAAAGCCCTGGAGAGACAAG GAAAGATAATATAG-3', synj1 T1205E_reverse: 5' -CTATATTATCTT TCCTTGTCTCTCCAGGGCTTTTGGGTGCT-3'; synj1 T1202A_forward: 5' -ATGGAAGCACCCAAAGCCCCTGGAACAACAAGG-3', synj1 T1202A_reverse: 5'-CCTTGTTGTTCCAGGGGCTTTGGGTGCTTCC AT-3'. Synj1 S1202A_forward: 5'-ATGGAAGCACCCAAAGCCCCTG GAACAACAAGG-3', Synj1 S1202A_reverse: 5' -CCTTGTTGTTCCAG GGGCTTTGGGTGCTTCCAT-3'; synj1. When performing coimmunoprecipitation with EGFP-endophilin1, EGFP was deleted from pEGFPC1-FLAG- $h S Y N J 1$. To delete EGFP from pEGFP-C1-FLAG- $h S Y N J 1$ by site-directed mutagenesis (QuikChange Lightning kit, Agilent, catalog \#210518), we used the following primers: forward, $5^{\prime}$-CGCTAGCGCTAC CGGTCGCCACCTCCGGACTCAGATC-3'; reverse, 5'-GCTTGAGCT CGAGATCTGAGTCCGGAGGTGGCGACCGG-3'. All oligonucleotides were synthesized by Integrated DNA Technologies and sequences validated by Genewiz.

Immunofluorescence and antibodies. Immunocytochemistry: Following imaging experiments all cells were stained for the DAergic neuronspecific marker, TH. Neurons were fixed in PFA (containing 4\% PFA, EMS, in $1 \times$ PBS) for $10 \mathrm{~min}$, permeabilized in $0.2 \%$ Triton, and blocked with $5 \% \mathrm{BSA}$ for $40-60 \mathrm{~min}$ in $37^{\circ} \mathrm{C}$. Primary antibodies were diluted in $5 \% \mathrm{BSA}$ and incubated with the cells at $37^{\circ} \mathrm{C}$ for $1 \mathrm{~h}$, and then incubated with 1:1000 dilution of AlexaFluor secondary antibodies (Thermo Fisher Scientific). The following primary antibodies were used: anti-TH antibody (monoclonal, Sigma-Aldrich catalog \#T2928 RRID:AB_477569, or polyclonal, Millipore catalog \#AB152 RRID:AB_390204, both used at 1:1000 dilution) and chicken anti-GFP (Thermo Fisher Scientific catalog \#A10262 RRID:AB_2534023, 1:1000 dilution), rabbit anti-synj1 (Novus catalog \#NBP1-87842 RRID:AB_11047653, 1:500 dilution), mouse antiLRRK2 clone N241A/N34 (NeuroMab, 1:500 dilution), and guinea pig anti-synapsin 1/2 (Synaptic Systems catalog \#106 004 RRID: AB_1106784, 1:500 dilution).

Optical setup and live cell imaging. For live cell imaging, cells were mounted on a custom-made laminar-flow stimulation chamber with 
constant perfusion (at a rate of $\sim 0.2-0.3 \mathrm{ml} / \mathrm{min}$ ) of a Tyrode's salt solution containing the following (in $\mathrm{mM}$ ): $119 \mathrm{NaCl}, 2.5 \mathrm{KCl}, 2 \mathrm{CaCl}_{2}, 2$ $\mathrm{MgCl}_{2}, 25$ HEPES, 30 glucose, $10 \mu \mathrm{M}$ CNQX, and $50 \mu \mathrm{M}$ D-AP5 and buffered to $\mathrm{pH}$ 7.40. $\mathrm{NH}_{4} \mathrm{Cl}$ solution containing the following (in $\mathrm{mM}$ ): $50 \mathrm{NH}_{4} \mathrm{Cl}, 70 \mathrm{NaCl}, 2.5 \mathrm{KCl}, 2 \mathrm{CaCl}_{2}, 2 \mathrm{MgCl}_{2}, 25 \mathrm{HEPES}, 30$ glucose, 10 $\mu \mathrm{M}$ CNQX, and $50 \mu \mathrm{M}$ AP5, buffered to $\mathrm{pH} 7.4$, was used to reveal total pHluorin expression for normalizing exocytosis. All chemicals were purchased from Sigma-Aldrich, except for bafilomycin A1 $(1 \mu \mathrm{M}$, Calbiochem, catalog \#196000-1SET). Temperature was clamped at $30.0^{\circ} \mathrm{C}$ at the objective throughout the experiment. Field stimulations were delivered at $10 \mathrm{~V} / \mathrm{cm}$ by A310 Accupulser and A385 stimulus isolator (World Precision Instruments). A 1 ms pulse was used to evoke single action potentials. Normalized exocytosis is determined by the size of the pHluorin signal relative to the maximum response upon a brief perfusion of the $\mathrm{NH}_{4} \mathrm{Cl}, \mathrm{pH} 7.4$, solution. Images were acquired using a highly sensitive, back-illuminated EM-CCD camera (iXon + model \# DU-897E-BV, Andor). An IX73 microscope was modified for laser illumination (Olympus). A solid-state $488 \mathrm{~nm}$ OPSL smart laser at $50 \mathrm{~mW}$ (used at $10 \%$ and output at $\sim 2 \mathrm{~mW}$ at the back aperture) was built into a laser combiner system for millisecond on/off switching and camera blanking control (Andor). Fluorescence excitation and collection were achieved through an Olympus PLAPON 60XO 1.42 NA objective using 525/50 m emission filter and 495LP dichroic filters (Chroma, catalog \#49002). Images were sampled at $2 \mathrm{~Hz}$ with an Imaging Workstation (Andor) driven by iQCORE-FST (version 2.x, Andor) iQ3.0 software.

Kinase assay. Kinase assay was performed as previously described (Li et al., 2010). FLAG- $h$ SYNJ1 was transfected in HEK293T cells by Lipofectamine 2000 (Thermo Fisher Scientific, catalog \#11668019) and affinity purified by anti-FLAG M2 Magnetic beads (Sigma-Aldrich catalog \#M8823; also M8823-1ML, M8823-5ML RRID:AB_2637089) after lysing with a Tris- $\mathrm{HCl}$ buffer containing $150 \mathrm{mM} \mathrm{Na}^{+}$and $1 \%$ Triton. Purified synj1 was resolved in SDS-PAGE (Thermo Fisher Scientific) and quantified based on colloidal Coomassie Blue staining. Tris-HCl buffer containing $15 \mathrm{~mm} \mathrm{Mn}^{2+}, 5 \mathrm{~mm}$ EGTA, and $0.1 \mathrm{mg} / \mathrm{ml} \mathrm{BSA}$ was used as the kinase buffer for LRRK2 kinase reaction at $37^{\circ} \mathrm{C}$ for $30 \mathrm{~min}$, supplemented by $0.6 \mathrm{~mm}$ ATP. For radioactive kinase assay, ${ }^{32} \mathrm{P}-\mathrm{ATP}$ (PerkinElmer Health Sciences, catalog \#BLU502H250UC) was added to the reaction system for autoradiograph detection. Full-length $h$ LRRK2 WT, $h$ LRRK2 G2019S, or $h$ LRRK2 D1994A were either purchased from Invitrogen or purified from HEK293T cells and used at 0-20 nм in the kinase reaction. G1023 (Genentech) was applied to the reaction at $0-5 \mu \mathrm{M}$.

Mass spectrometry analysis. To identify the specific residue(s) on synj1 that can be modified by LRRK2, we performed two lines of mass spectrometry analyses. In the first analysis, we performed kinase assays for human synj1 (hsynj1) purified from HEK293T cells by incubating it with $0 \mathrm{nM}$ (as control) or $50 \mathrm{nM}$ Invitrogen purified full-length $h$ LRRK2 G2019S. Synj1 was then separated from LRRK2 on an SDS-PAGE for further enzyme digestion and phosphor group detection. Both trypsin digestion and lys-C/glu-C double digestion were used to enrich coverage for different regions of the synj 1 protein. In the second analysis, $h$ synj 1 was coexpressed with $h$ LRRK2 kinase dead (LRRK2 D1994A, as control) or $h$ LRRK2 G2019S in HEK293T cells for $2 \mathrm{~d}$ before cells were lysed and proteins were separated on an SDS-PAGE. The Scaffold software was used to analyze the phosphor groups. This work was performed at the Mass Spectrometry Core (by Dr. Rong Wang and colleague) at Mount Sinai.

Anti-synj1 pT1205 antibody generation and purification. Phosphor peptide (PGpTTRKDNIGRS-Cys) was synthesized and injected into 3 rabbits (Cocalico Biologicals). The prebleed and the third-bleed sera were collected from all 3 rabbits and tested for specificity by in vitro kinase assay. The third-bleed serum from one of the rabbits with the best efficacy and specificity was selected for phosphor-specific antibody purification. The nonphosphor peptide (PGTTRKDNIGRS) was used to remove nonspecific binding.

Coimmunoprecipitation. EGFP-endophilin 1 and FLAG- $h$ synj1 WT or mutants were transfected at 1:1 molar ratio in HEK293T cells. Transfected HEK293T cells were harvested and suspended in cell lysis buffer (50 mm Tris $\mathrm{HCl}, \mathrm{pH} 7.5,150 \mathrm{~mm} \mathrm{NaCl}, 1 \%$ Triton X-100, and mini- complete protease and phosphatase inhibitor mixture, Thermo Fisher Scientific, Pierce, catalog \#88669). The cell lysate was cleared at $12,000 \times$ $g$ for $10 \mathrm{~min}$ at $4^{\circ} \mathrm{C}$. After quantification using the BCA assay, $600 \mu \mathrm{g}$ of total lysate was used to incubate with rabbit anti-GFP (Thermo Fisher Scientific catalog \#A-11122 also A11122 RRID:AB_221569) overnight, followed by $1 \mathrm{~h}$ incubation with Dynabeads Protein G (Thermo Fisher Scientific, $10004 \mathrm{D}$ ) at $4^{\circ} \mathrm{C}$. The beads were washed with Tris- $\mathrm{HCl}$ buffer 3 times and eluted by a sample buffer (Novex, catalog \#NP0007). The immunoprecipitated and coimmunoprecipitated proteins were analyzed on a SDS-PAGE gel followed by Western blotting using anti-GFP and anti-FLAG, respectively.

Behavioral assays. Male transgenic mice and their littermate controls (12 months) were tested for general locomotor activity in an open field chamber in the dark room for $60 \mathrm{~min}$. Motor coordination was assessed on an accelerated Rota-rod and a challenge beam. All tests were performed in a double-blinded manner.

1. Open-field test. An individual mouse was placed into the center of a $16 \times 16$ inch cage with a Versamax monitor system (Accuscan) in a quiet dark room. The mouse horizontal and vertical movement was monitored and recorded for $60 \mathrm{~min}$ by a grid of 32 infrared beams at ground level and 16 elevated ( 3 inch) beams.

2. Accelerated Rota-rod test. A mouse was placed on a rotating rod with acceleration from 4 to 40 RPM within $5 \mathrm{~min}$. Each mouse was trained for 2 trials before the test. The duration a mouse spent on the accelerated Rota-rod was averaged for consecutive 3 trials spaced by $15 \mathrm{~min}$.

3. Challenging beam traversal test. Mice were trained for $2 \mathrm{~d}$ to walk on an elevated tapering beam that measures $100 \mathrm{~cm}$ in length and consists of four sections with different widths $(3.5,2.5,1.5$, and 0.5 $\mathrm{cm}$ ) (Fleming et al., 2004). On each training day, the mouse walks across the beam 2 times in the home cage assisted mode and then 5 times in the unassisted mode. On the experiment day, a set of matching mesh wires was placed on top of the beam. Animals were then videotaped while traversing the grid-surfaced beam for consecutive five trials with 15 min spacing. The total steps and slips were scored and analyzed in a double-blinded fashion.

Stereology analysis. Mice were perfused and fixed by freshly made $4 \%$ PFA. Brains were dissected immediately and fixed again in 4\% PFA followed by $15 \%$ and $30 \%$ sucrose. Fixed brains were imbedded in the OCT-compound media (Sakura) and let set in liquid nitrogen. MB brain tissues were cryo-sectioned at $40 \mu \mathrm{m}$ in thickness using a Leica CM3050s cryostat and stored in an antifreeze media containing $30 \%$ ethanol glycol, $25 \%$ glycerol, and 5\% phosphate buffer. For stereology counting, 1 in every 5 sections was selected with a random start and a total of 8 brain slices on average were used for each mouse for IHC labeling for TH, including $\mathrm{DAB}$ enhancement, followed by cresyl violet staining to reveal all neurons. A Zeiss Axioplan2 was used for tissue slice imaging with a $20 \times$ objective, and Stereo Investigator was used to estimate the total number of neurons in the region of interest using the following parameters: frame sizes, $150 \times 150 \mu \mathrm{m}$; grid sizes, $250 \times 250 \mu \mathrm{m}$; top guard zone height, $2 \mu \mathrm{m}$; and optical dissector height, $8 \mu \mathrm{m}$. These parameters yielded a coefficient of error $<10 \%$ throughout the analysis.

Data analysis and statistics. The number of repetitions and sample sizes are determined by intrinsic variation of the dataset. For cell culture-based imaging study, data were obtained from at least 2 or 3 independent cultures. For biochemical studies, each result represents 4 or more repetitions. All sample sizes are indicated in the figure legends. In the imaging study, typically, 15-50 nerve terminals with consistent responses were selected for analysis for each cell. More than three replications were typically used for each experimental setting to ensure the stability of the cell and the optical system. For the LRRK2 overexpression study presented in Figure 4, LRRK2 G2019S was coexpressed with vMAT2pHluorin. Post hoc immunocytochemistry was used to determine whether the neuron we analyzed had LRRK2 overexpression by normalizing the LRRK2 immunofluorescence at the soma to the average of those from 4 or 5 neighboring untransfected cells. LRRK2 overexpression (GS OE) was determined at $20 \%$ cutoff. Few $(\sim 5 \%)$ outliers (if data fall outside the range of mean $\pm 3 \times \mathrm{SD}$ ) were excluded. For each dataset 
A

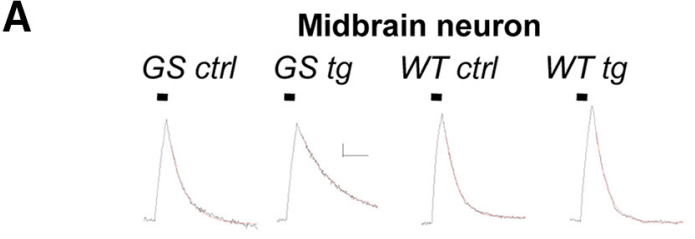

C

Midbrain neuron
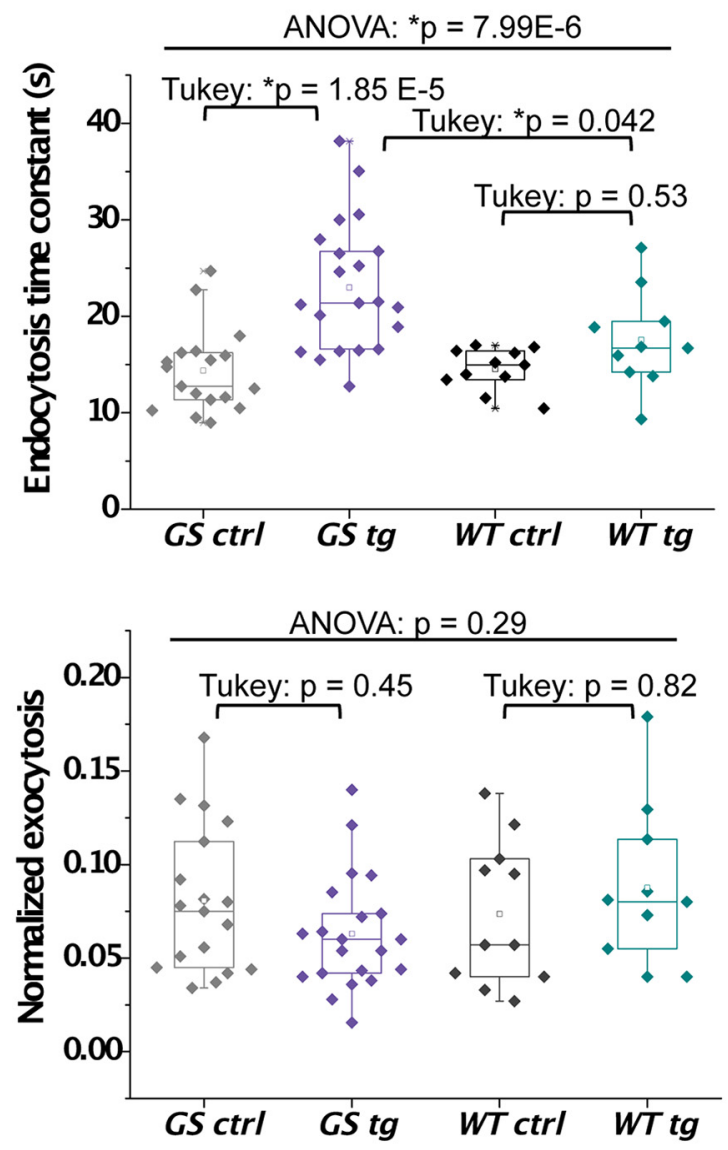

B

Cortical neuron

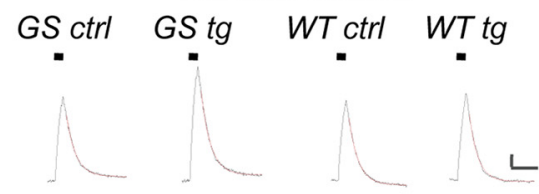

Cortical neuron
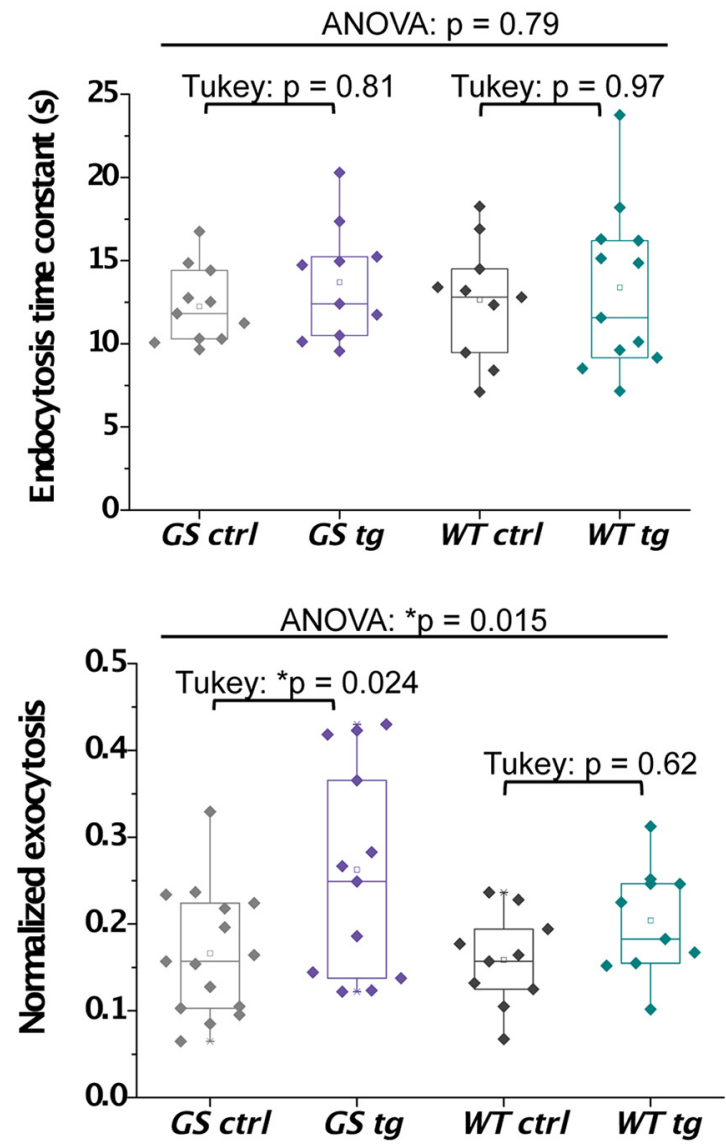

Figure 1. PD-linked LRRK2 G2019S mutation leads to MB neuron-specific impairment in SV endocytosis. $A, B$, Representative pHluorin traces (in black) in response to $10 \mathrm{~Hz}$, 10 s field stimulations (short black bars) obtained from midbrain $(\boldsymbol{A})$ and cortical (B) neurons with different genetic backgrounds: from left to right: GS ctrl (N=18), GStg $(N=21), W T$ ctrl (N=11), and WTtg $(N=11)$. Red traces represent the fitted single exponential decay function. Scale bars: $\boldsymbol{A}, 25 \mathrm{~s}, 0.15 \% \mathrm{NH}_{4} \mathrm{Cl}$ response; $\boldsymbol{B}, 25 \mathrm{~s}, 0.25 \% \mathrm{NH}_{4} \mathrm{Cl}$ response. $\boldsymbol{C}, \boldsymbol{D}$, Comparison of endocytosis time constants ( $\tau$ obtained from the single exponential decay fit) (top two panels) and the amount of exocytosis by normalizing to the peak of the $\mathrm{NH}_{4} \mathrm{Cl}$ response (bottom two panels) for cultured midbrain neurons $(\boldsymbol{C})$ and cultured cortical neurons $(\boldsymbol{D})$ derived from different transgenic backgrounds. For LRRK2 immunofluorescence in cultured MB neurons, see Figure 1-1 (available at https://doi.org/10.1523/JNEUROSCI.0964-17.2017.f1-1). For comparison of exocytosis and endocytosis kinetics between $\mathrm{TH}^{+}$and $\mathrm{TH}^{-}$neurons, see Figure 1-2 (available at https://doi.org/10.1523/JNEUROSCI.0964-17.2017.f1-2).

acquired, a test for normality was performed using the built-in function in OriginPro 8.2. Two-way ANOVA was used when comparing two variables, such as Figure 2. One-way ANOVA test was used for multiple group comparisons followed by Tukey's post hoc test. Paired Student's $t$ test was used to test the paired observation on the same neuron before and after the drug (see Fig. 3). Exact $p$ values and $F$ values were printed on the figure. All data (but see Fig. 3) were presented in box-and-scatter plot, where the box represents $25 \%-75 \%$ distribution of the data, the whiskers represent $5 \%-95 \%$ distribution of the data, the square indicates the mean, and the line indicates the medium.

\section{Results}

LRRK2 G2019S mutation leads to an impairment in SV endocytosis in midbrain but not in cortical or hippocampal neurons

To dissect the mechanism underlying the pathogenic effect of LRRK2 G2019S (GS), we investigated the nerve terminal func- tions of $\mathrm{MB}$ neurons and cortical neurons derived from the $B A C$ mice previously established in our group (Li et al., 2010). Quantification of LRRK2 levels in cultured MB neurons derived from LRRK2 GS and LRRK2 WT BAC mice through anti-LRRK2 antibody immunofluorescence intensity indicated a near twofold elevation of LRRK2 (Fig. 1-1A, available at https://doi.org/10.1523/ JNEUROSCI.0964-17.2017.f1-1), which was substantially lower than our previous Western blot estimates (6- to 8-fold) for the whole brain (Li et al., 2010). Despite the existing evidence for the potential role of LRRK2 in regulating presynaptic function (Shin et al., 2008; Matta et al., 2012; Piccoli et al., 2014; Belluzzi et al., 2016), it has been difficult to demonstrate endogenous LRRK2 localization at the nerve terminal and the relevance to PD remains elusive. By expressing LRRK2 GS transgene into cultured $\mathrm{MB}$ neurons, we found that LRRK2 could be targeted to express 
A

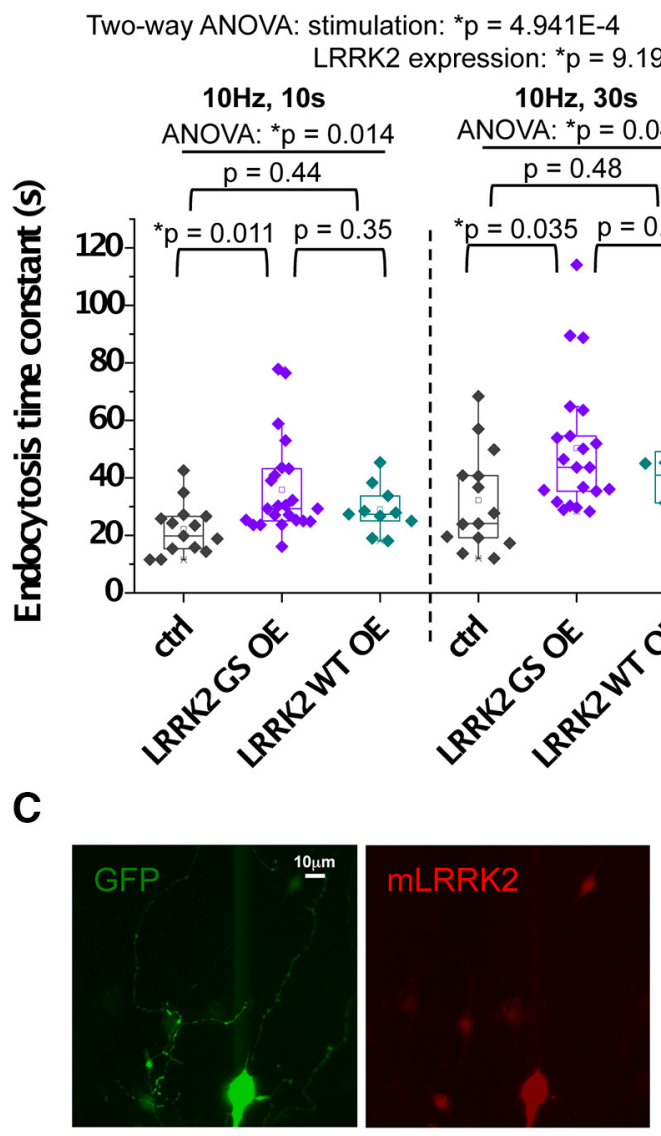

B

Two-way ANOVA: stimulation: ${ }^{*} p=8.469 E-5$

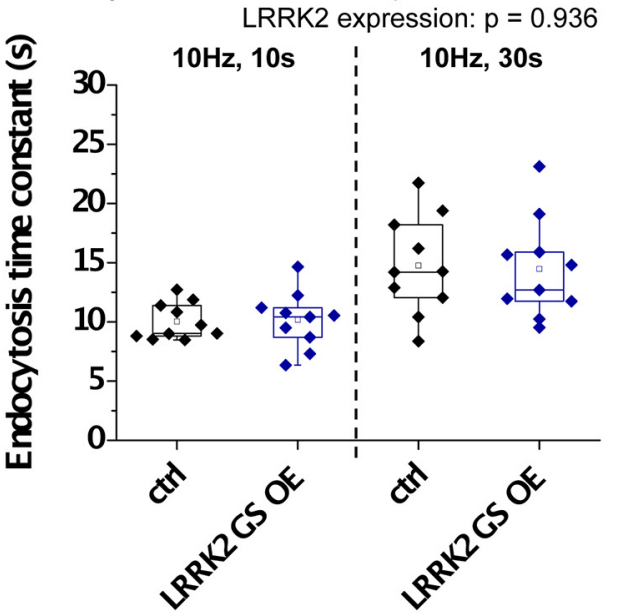

D

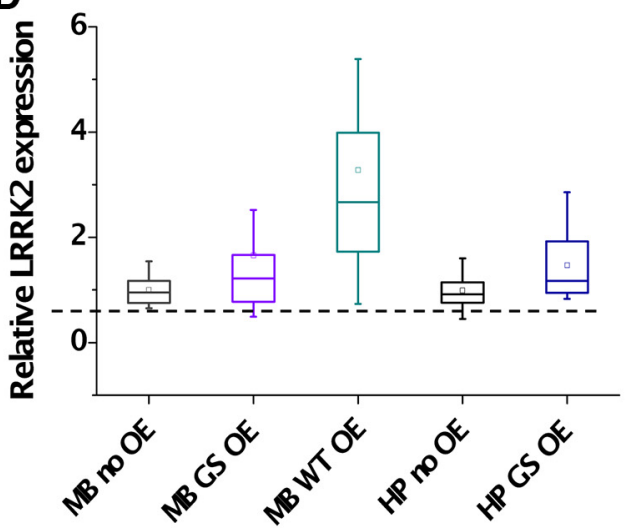

Figure 2. LRRK2 G2019S overexpression in rat MB neurons, but not in hippocampal neurons, leads to slowed endocytosis. $\boldsymbol{A}$, Endocytosis time constant after $10 \mathrm{~Hz}, 10 \mathrm{~s}$ and $10 \mathrm{~Hz}$, $30 \mathrm{~s}$ stimulations in WT rat MB neurons ( $N=14$ ) and those overexpressing either LRRK2 G2019S ( $N=23$ ) or LRRK2 WT ( $N=10)$. B, Endocytosis time constant after 10 Hz, 10 s (left) and 10 Hz, 30 s (right) stimulations in WT rat hippocampal (HP) neurons $(N=10)$ and those overexpressing LRRK2 G2019S (LRRK2 GS OE, $N=10)$. C, Representative immunofluorescence image for rat MB culture transfected with vMAT2-pHluorin and mouse LRRK2. D, Summary for the relative LRRK2 overexpression level at the cell body in different neurons. LRRK2 GS was overexpressed at a similar $50 \%$ level in both the MB and the HP neurons.

at the axonal terminals of MB DAergic and non-DAergic neurons (Fig. 1-1B, available at https://doi.org/10.1523/JNEUROSCI. 0964-17.2017.f1-1). We then applied an optical assay using pHluorin, a variant of GFP whose fluorescence is quenched by protonation (Sankaranarayanan et al., 2000). When targeted to the acidic lumen of SVs, pHluorin is quenched but fluoresces upon exocytosis when pHluorin is exposed to the extracellular buffer, $\mathrm{pH}$ 7.4. Previously, we have shown that conjugating pHluorin to vesicular transporters, such as vesicular glutamate transporter 1 (vGLUT1) or vesicular monoamine transporter 2 (vMAT2), allows the examination of SV kinetics at unprecedented precision (Ariel and Ryan, 2010; Pan and Ryan, 2012). These optical reporters have provided a great means for investigating the presynaptic regulation for GPCR-mediated DA signaling, which is inaccessible by conventional patch-clamp recording.

vMAT2-pHluorin and vGLUT1-pHluorin were expressed, respectively, in cultured $\mathrm{MB}$ neurons and cortical neurons derived from the transgenic mice (GStg) and their littermate controls (GS $(t r l)$. DAergic neurons were determined by post hoc immunoreactivity to TH. SV endocytosis in response to a brief $10 \mathrm{~Hz}, 10 \mathrm{~s}$ stimulation was significantly slowed in MB neurons from LRRK2 GStg mice compared with their littermate control (GS $\mathrm{ctrl}$ ), whereas the exocytosis was not affected (Fig. $1 A, C$ ). In contrast, the slowed endocytosis kinetics in MB neurons was not observed in LRRK2 GStg cortical neurons (Fig. $1 B, D$ ). The amount of exocytosis, however, was enhanced, which is consistent with previous reports (Beccano-Kelly et al., 2014; Plowey et al., 2014; Belluzzi et al., 2016). Interestingly, we did not observe any difference in endocytic or exocytic kinetics between DAergic and nonDAergic neurons in these cultures (Fig. 1-2, available at https:// doi.org/10.1523/JNEUROSCI.0964-17.2017.f1-2). Transient overexpression of LRRK2 GS mutant also resulted in defective SV endocytosis in cultured rat $\mathrm{MB}$ neurons but not in hippocampal neurons (Fig. 2). Our data herein revealed a MB-selective defect in SV endocytosis regulated by LRRK2.

To distinguish the effect of LRRK2 GS from the consequence of LRRK2 protein overexpression, we examined SV endocytosis in neurons derived from LRRK2 WT BAC transgenic (WTtg) mice, in which WT LRRK2 proteins are overexpressed at a similar level to LRRK2 GS proteins in the brains of BAC mice (Li et al., 2010) (Fig. 1-1A, available at https://doi.org/ 10.1523/JNEUROSCI.0964-17.2017.f1-1). Our results show that the endocytosis time constant in WTtg MB neurons was not different from its littermate controls ( WT ctrl; Fig. 1A,C). Consistently, rat-derived WT MB neurons overexpressing WT LRRK2 also failed to alter endocytosis kinetics (Fig. 2), suggesting that the 
A

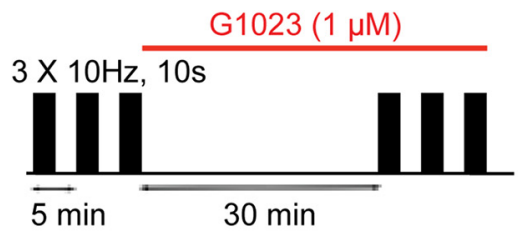

B

B Cortical neuron

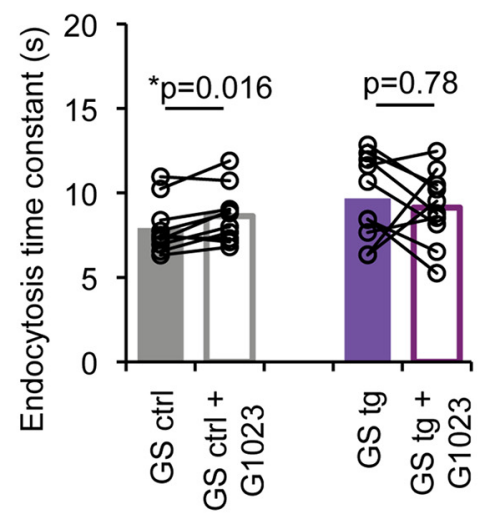

C

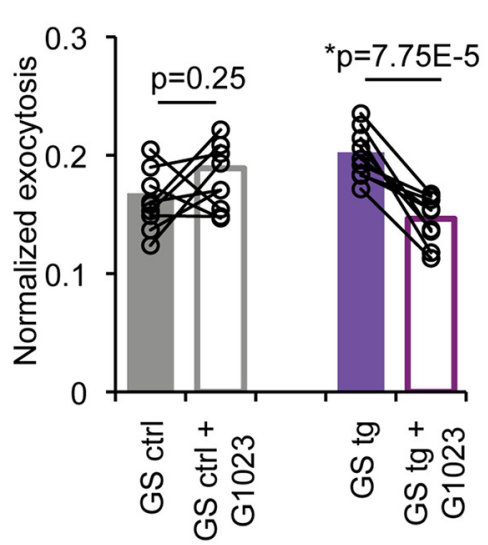

MB neuron

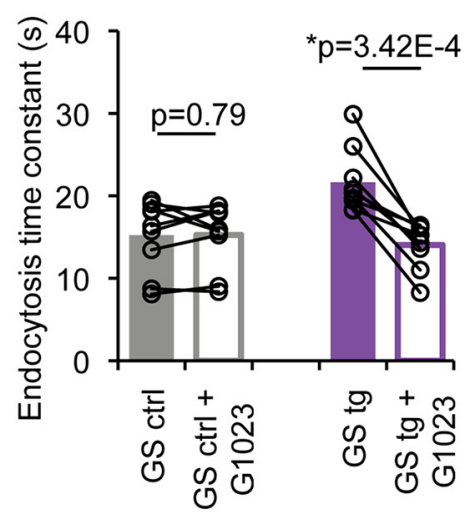

MB neuron

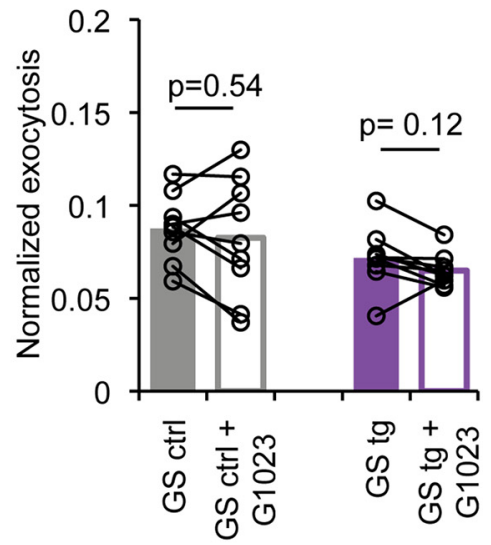

Figure 3. Impaired SV trafficking is mediated by hyperactivity of LRRK2 PD mutant G2019S. $\boldsymbol{A}$, Experimental scheme of LRRK2 kinase inhibitor test for each neuron. $\boldsymbol{B}, \boldsymbol{C}$, Comparison of endocytosis time constant $(\boldsymbol{B})$ and normalized exocytosis $(\boldsymbol{C})$ before and after 30 min incubation with G1023 $(1 \mu \mathrm{M})$ for GS ctrl cortical neurons $(N=10)$, GStg cortical neurons $(N=10), G S$ ctrl MB neurons $(N=9)$, and GStg MB neurons $N=9)$. $p$ values are from paired $t$ tests.

GS mutation, rather than LRRK2 protein overexpression, is attributable to the SV endocytic defect.

\section{Impaired SV trafficking is caused by hyperactivity of LRRK2 PD mutant G2019S}

To further assess the contribution of hyperactive GS kinase (West et al., 2005) to dysfunctional SV trafficking, we applied LRRK2 kinase-specific inhibitor G1023 (Sheng et al., 2012) to the cultured neurons (Fig. $3 A$ ) and examined SV dynamics in the same neuron before and after $30 \mathrm{~min}$ incubation of the drug. We found that littermate ( $G S \mathrm{ctrl}$ ) neurons displayed little or no sensitivity to the kinase inhibitor, whereas the slowed endocytosis in GStg MB neurons as well as the enhanced exocytosis in GStg cortical neurons were effectively rescued after incubation with G1023 (Fig. $3 B, C$ ). Collectively, our results suggest that the hyperactive kinase activity caused by the PD-linked LRRK2 G2019S mutation leads to selective impairment in SV trafficking in distinct neuronal types.

\section{MB neurons carrying LRRK2 G2019S and $S Y N J 1$ heterozygosity have impaired endocytosis and exocytosis} A previous study suggested a genetic interaction between lrrk and endoA in drosophila NMJ. EndoA haploinsufficiency rescued the slowed endocytosis in lrrk-null mutant (Matta et al., 2012). Given the close partnership between endoA and synj1 during SV recycling (Cestra et al., 1999; Schuske et al., 2003; Verstreken et al., 2003; Chang-Ileto et al., 2011; Dong et al., 2015), we then tested whether LRRK2 and SYNJ1 are in the same signaling pathway in the mammalian system. Unlike the drosophila NMJ, $L R R K 2$ deletion did not alter SV endocytosis in mouse MB neurons with brief 10 $\mathrm{Hz}, 10$ s stimulations (knock-out: $16.60 \pm$ $0.97 \mathrm{~s}, N=7$; wild-type: $16.47 \pm 1.21 \mathrm{~s}$, $N=11, p=0.52$, two-tailed Student's $t$ test). We therefore focused on $L R R K 2$ GStg and SYNJ1 heterozygous mice. Cortical neurons derived from $S Y N J 1^{+/-}$ mice did not exhibit endocytic deficits, although homozygous deletion of SYNJ1 resulted in substantial slowing of endocytosis kinetics at the synapse and perinatal lethality in mice (Mani et al., 2007). Consistent with the previous study, we observed similar results by expressing vGLUT1pHluorin in $S Y N J 1^{+/+},+/-$, and ${ }^{-/-}$cortical neurons (ANOVA, $p=4.99 \mathrm{E}-14$, $S_{Y N J 1}{ }^{+/-}: 14.81 \pm 1.63 \mathrm{~s}, N=8 \mathrm{com}-$ pared with $S Y N J 1^{+/+}: 12.55 \pm 1.01 \mathrm{~s}, N=$ $15, p=0.83$, Tukey's post hoc; SYNJ1 ${ }^{-1-}$ : $67.17 \pm 5.69 \mathrm{~s}, N=8, p=0$ compared with $\mathrm{SYNJ1}^{+/+}$neurons, Tukey's post hoc). However, SYNJ1 ${ }^{+/-} \mathrm{MB}$ neurons exhibited significantly slowed endocytosis (Fig. 4A,C), reminiscent of LRRK2 GStg $\mathrm{MB}$ neurons (Fig. 1). This result suggests an enhanced sensitivity of $\mathrm{MB}$ neurons (relative to cortical neuron) to reduced SYNJ1 expression for SV endocytosis. The phenotypic resemblance in SV endocytosis for LRRK2 GStg and SYNJ1 ${ }^{+/-}$MB neurons suggests that the two genes may share the same pathogenic pathway for disrupting SV trafficking.

To further examine the genetic interaction of $L R R K 2$ GS and SYNJ1 heterozygosity, we then expressed LRRK2 GS in SYNJ1 $1^{+/-}$ MB neurons. The results indicate that LRRK2 G2019S expression did not exacerbate the slowed endocytosis due to SYNJ1 heterozygosity (Fig. 4A,C), consistent with the notion that LRRK2 G2019S shares the same pathogenic signaling as SYNJ1 insufficiency in impairing SV endocytosis in these neurons. However, SV exocytosis was substantially reduced compared with $S Y N J 1^{+/+} \mathrm{MB}$ neurons (Fig. $4 B, D$ ), whereas neither $S Y N J 1^{+/-}$nor LRRK2 GS alone altered exocytosis. The disruption of SV exocytosis in $\mathrm{MB}$ neurons carrying both LRRK2 GS and $S Y N J 1^{+/-}$is unexpected and 
not understood at present. It may be related to the role of synj1 in balancing the level of $\mathrm{PI}(4,5) \mathrm{P} 2$, which is involved in exocytosis regulation (Di Paolo and De Camilli, 2006; van den Bogaart et al., 2012; Honigmann et al., 2013), or related to the other roles of LRRK2 GS in altering DA transmission (Tong et al., 2009; Li et al., 2010; Melrose et al., 2010; Beccano-Kelly et al., 2015).

Transgenic mice carrying both $L R R K 2$ G2019S mutation and $S Y N J 1^{+/-}$display behavioral deficits

We next tested the genetic interaction of LRRK2 PD mutant and SYNJ1 deficiency using animal models by crossing LRRK2 GStg mice with SYNJ1 $1^{+/-}$mice and examined the vulnerability of the LRRK2 Gtg; SYNJ1 $^{+/-}$(double transgenic, Dtg) mice. We performed a set of behavioral analysis in cohorts of 1-year-old male mice with four genotypes: WT LM, Dtg, LRRK2 GStg, and $S Y N J 1^{+/-}$. In the open field study, we found that Dtg mice are similar to control groups (WT LM) in general locomotor functions (Fig. 5A). However, $D t g$ mice spent less time in the center areas of the testing chambers compared with $S Y N J 1^{+/-}$mice (Fig. 5B) but showed no difference compared with WT LM. In the challenging beam test, which is a sensitive test for fine motor coordination (Fleming et al., 2004), Dtg mice lagged behind by a moderate but significant two steps compared with the WT LM (Fig. 5D). Furthermore, the Dtg mice displayed a trend toward shorter duration on the accelerated Rota-rod than WT LM (Fig. 5C). Thus, the behavioral alterations in Dtg mice further supports a genetic interaction between LRRK2 GS and SYNJ1 insufficiency that renders LRRK2 GS more vulnerable to motor function challenges. We also performed an unbiased stereological counting of $\mathrm{TH}^{+}$DAergic neurons in the midbrains. The results did not reveal obvious reduction of $\mathrm{TH}^{+}$ neurons in Dtg (Fig. 5E,F) compared with control (WT LM) mice, suggesting that the behavioral changes in Dtg mice are likely due to the functional alteration rather than degeneration. The lack of degeneration in Dtg mice also suggests that neuronal function deficits represent an early pathological change in the disease process.

\section{LRRK2 phosphorylates synj1 in vitro and impairs its interaction with endophilin}

To determine the potential molecular basis for LRRK2 and synj1 interaction, we tested whether LRRK2 phosphorylates synj1 and thereby deregulates SV trafficking. We first performed phosphorylation assay with purified full-length LRRK2 GS protein (Guaitoli et al., 2016) and synj1 in the presence of radioactive ${ }^{32} \mathrm{P}$-ATP. Strong ${ }^{32} \mathrm{P}$ labeling was detected for synj1 as well as for LRRK2 due to autophosphorylation (Fig. $6 A$ ), suggesting that synj1 can be phosphorylated by LRRK2 in vitro. We next performed mass spectrometry analyses to identify potential phosphorylation sites in synj1. In two independent studies (detailed in Experimental Procedures), only one conserved threonine (T1205) in the proline-rich domain (PRD) of hsynj1 was consistently phosphorylated in the presence of LRRK2 (Fig. 6B).

Using a phospho-specific antibody against hsynj1 pT1205 (generated in this study), we detected a near 15-fold increase of pT1205 synj1 signal in the presence of LRRK2 GS compared with the WT LRRK2 protein (Fig. 6C,D). Incubation with a kinasedead LRRK2 mutant (D1994A) yields no signal in pT1205 synj1 (Fig. 6C,D). Moreover, LRRK2 kinase-specific inhibitor G1023 reduces the intensity of pT1205 synj1 signal (Fig. $6 E$ ), suggesting LRRK2-specific modification.

The PRD of synj 1 binds endophilin and contains many serines and threonines prone to phosphorylation. For example, cdk5 phosphorylates $h S 1202 / m S 1144$ (but not $h \mathrm{~T} 1205 / m \mathrm{~T} 1147$ ) (Lee et al., 2004), which is only three amino acids preceding $h \mathrm{~T} 1205$. To study the effect of T1205 phosphorylation in synj1 function, we examined how phosphomimetic (synj1 T1205E) and phosphodead (synj1T1205A) mutants of hsynj1 may alter endophilin binding. We expressed GFP-tagged endophilinA1 (endo-GFP) with either WT or mutant forms of synj1 in HEK293T cells and performed a coimmunoprecipitation assay. Consistent with the previous findings, the binding between S1202A synj1 and endoA was not impaired (Fig. 6F) (Lee et al., 2004); however, both T1205E and T1205A mutations significantly reduced synj1's binding to endophilin (Fig. $6 F, G$ ). The reduction of endophilin binding for synj1 T1205A or T1205E suggests that T1205 of PRD is critical for endophilin interaction and structurally vulnerable for perturbation. Because of the lack of sufficient sensitivity of the antibody, we were unable to detect T1205 phosphorylation of synj1 in mouse brains. However, a recent study in fly model 


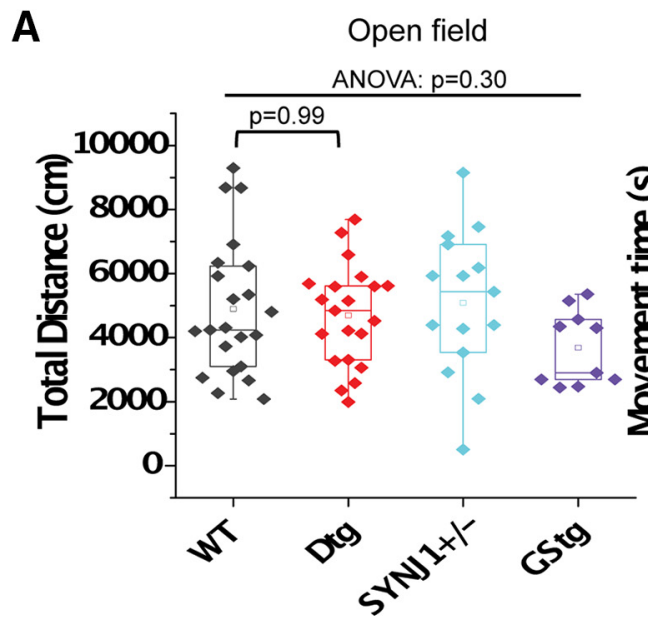

C

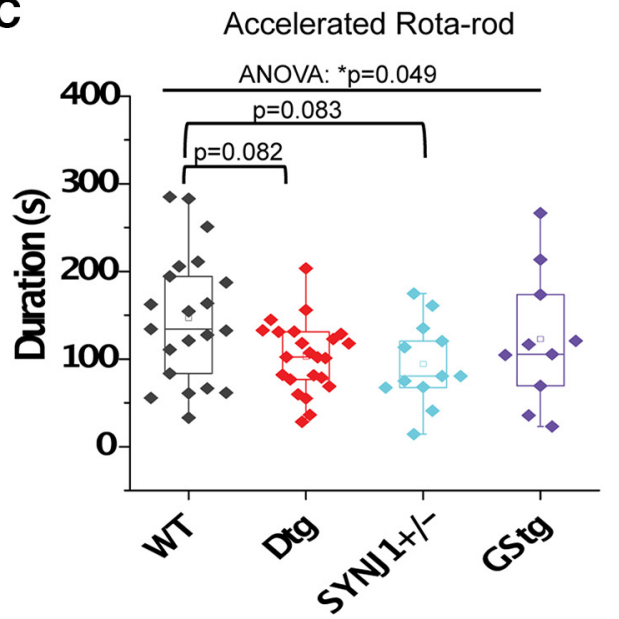

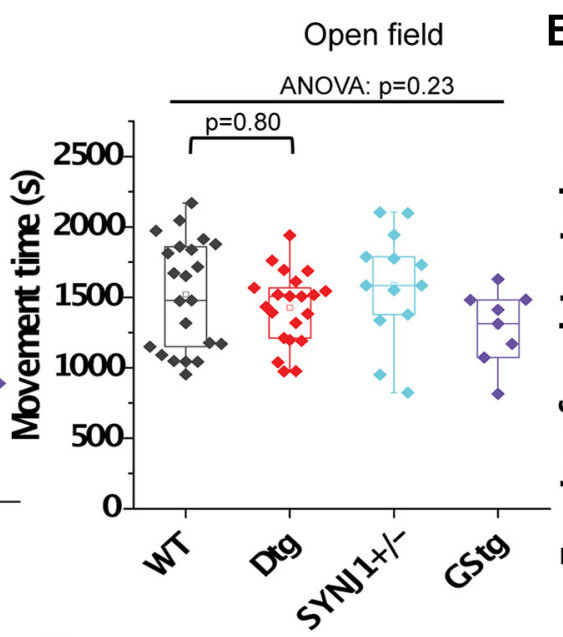

D

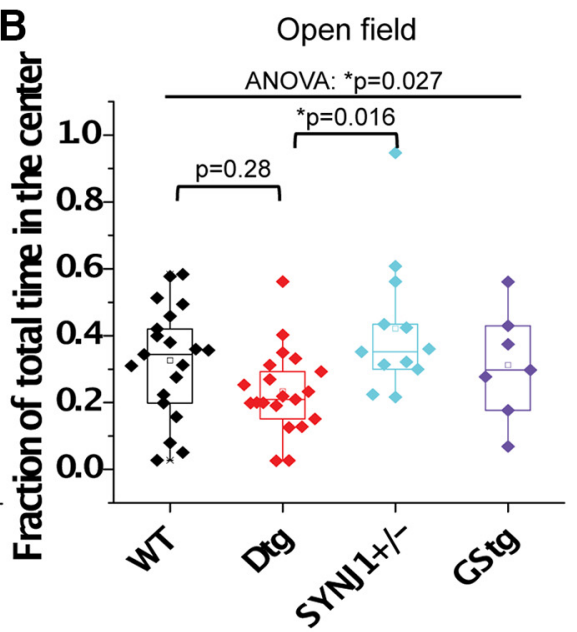

Challenging beam
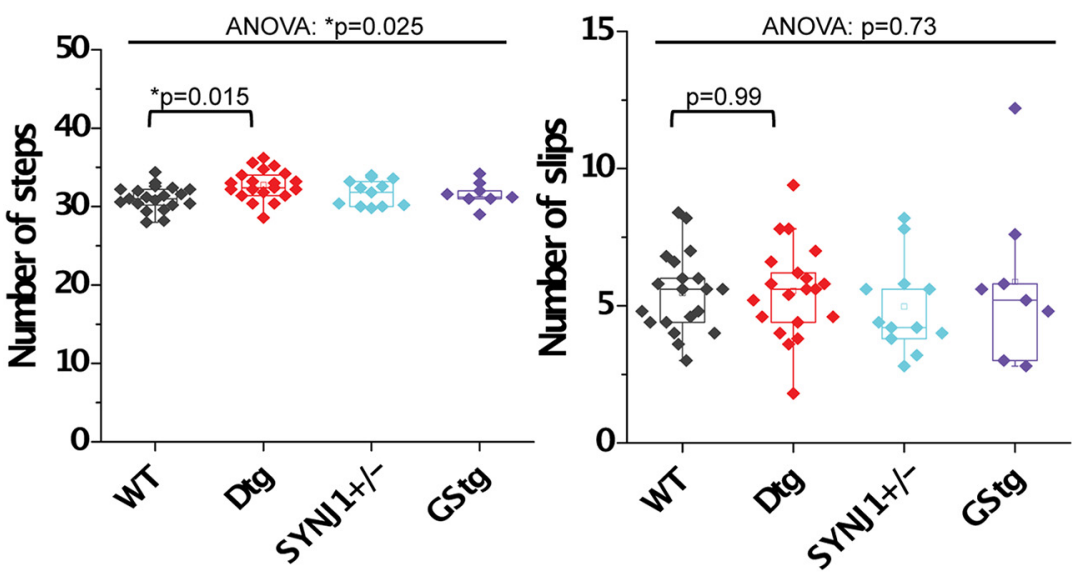

E
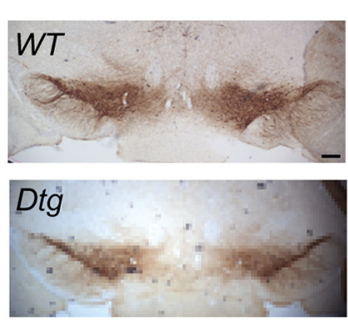

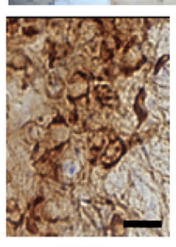

WT
$F$

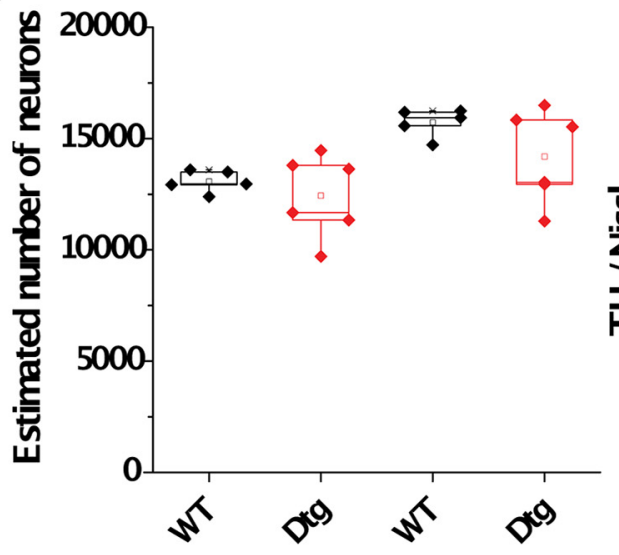

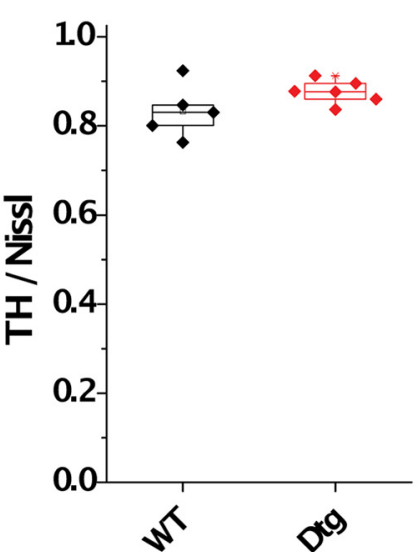

Figure 5. Dtg mice display altered motor functions. $A-D$, Male mice at 1 year of age with the following genotypes: WT littermates $\left(N=21\right.$, black), SYNJ1 ${ }^{+/-}(N=12$, cyan), and $L R R K 2$ G2019S transgenic (LRRK2 GS) $\left(N=10\right.$, purple) and $L R R K 2 G S ; S Y N J 1^{+/-}(D t g)$ mice $(N=23$, red) are subjected to open field test $(\boldsymbol{A}, \boldsymbol{B})$, accelerated Rota-rod test $(\boldsymbol{C})$, and challenging beam traversal test (D). A, Scattered and box plot summarizing total distance and movement time in the open field test. $\boldsymbol{B}$, Summary of time animal spent in the center versus the periphery of the open field chamber for all littermates. C, Summary of the duration animal spent on the accelerated Rota-rod. D, Number of steps and total number of slips from averaging 5 separate trials in the challenging beam traversal test for all littermates. $\boldsymbol{E}$, Representative images showing TH immunolabeling (DAB enhanced, brown) and Nissl counterstaining (blue) at the ventral midbrain from a Dtg mouse and a WT littermate. Scale bars, $20 \mu \mathrm{M}$. F, Stereology analysis estimating total number of TH and Nissl-positive neurons in Dtg mice $(N=5)$ and WT littermates $(N=6)$ as well as the percentage of TH-positive neurons did not reveal any difference.

demonstrated that PD mutant R1441C of human LRRK2 phosphorylates synj1 at PRD domain (Islam et al., 2016), supporting the idea that LRRK2 can phosphorylate synj1 in vivo. Nonetheless, the validation of the above idea in mammals awaits future experiments with the development of antibodies with greater sensitivity.

\section{Discussion}

Our data demonstrate that the most common PD mutation LRRK2 G2019S disrupts SV endocytosis in DAergic neurons and appears selective for $\mathrm{MB}$ but not cortical or hippocampal neurons. The pathogenic function of LRRK2 mutant may require LRRK2 kinase activity. Our study indicates that LRRK2 G2019S 
A

${ }^{32} \mathrm{P}$ radioactive kinase assay

15nM LRRK2 - +

FLAG-synj $1++$

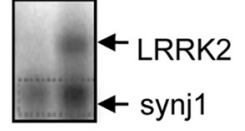

B

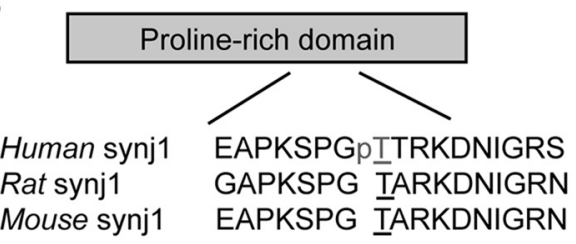

C

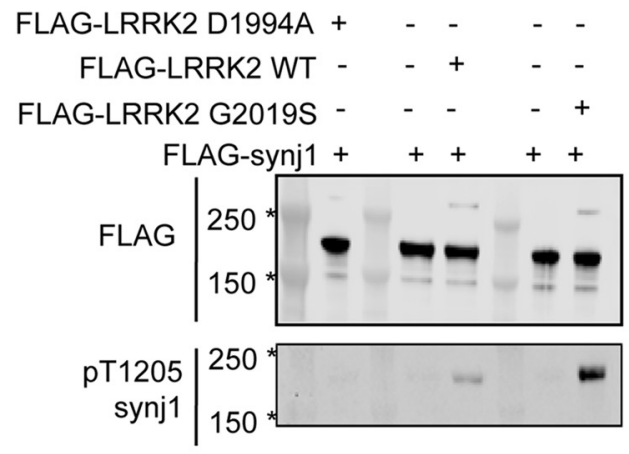

D

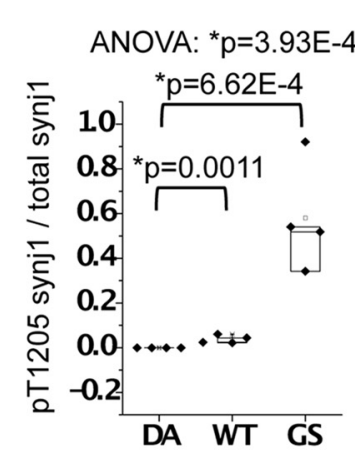

E

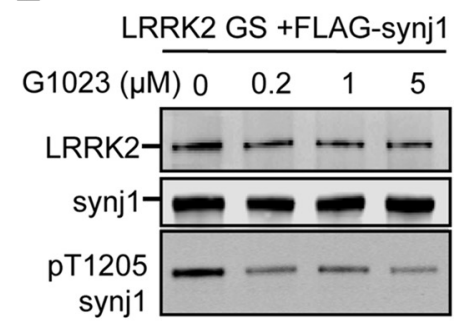

G

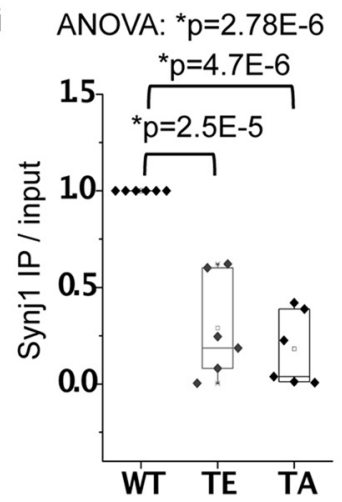

Figure 6. LRRK2 phosphorylates synj1 and phosphomimetic synj1 display reduced endophilin interaction. $A$, Radioactive kinase assay showing enhanced ${ }^{32} \mathrm{P}$ signal for synj1 after incubation with $15 \mathrm{~nm}$ Invitrogen full-length human LRRK2 G2019S protein. B, Mass spectrometry analysis reveals a threonine at 1205 within the proline-rich domain of human synj1 as the phosphorylation substrate of LRRK2 G2019S. This threonine also exhibits conservation in two rodent forms of synj1. C, Purified kinase-dead (D1994A), WT, and kinase gain-of-function mutant (G2019S) of LRRK2 were used to incubate with synj1 immunoprecipitated by anti-synj1 antibody in a kinase assay, followed by immunoblotting with anti-pT1205 synj1 antibody $(N=5)$. $D$, Summary of the pT1205 synj1 signal in C from four separate experiments. $\boldsymbol{E}$, Reduced pT1205 signal in response to increasing amount of LRRK2 kinase inhibitor (G1023) $(0,0.2,1$, and $5 \mu \mathrm{M})$. $\boldsymbol{F}$, Coimmunoprecipitation of synj1 by endophilinA (endoA). WT and mutant forms of synj1, including FLAG-synj1 S1202A, FLAG- synj1 T1205E, and FLAG-synj1 T1205A, were coexpressed with GFP-endoA in HEK293T cells. Coexpression of WT synj1 and GFP was used as a negative control for IP. G, Box plot summarizing the reduced endophilinA binding for synj1 T1205E and synj1 T1205A (N = 6).

shares a pathogenic pathway with SYNJ1 insufficiency in the deregulation of SV recycling. In addition, they play expanded roles in facilitating each other's function in PD pathogenesis. Our biochemical evidence of LRRK2-mediated phosphorylation of synj1, which is supported by a previous in vivo study (Islam et al., 2016), provides a potential mechanism for the merge of the pathogenic signaling of the two PD risk genes (PARK8 and PARK20) in a brain region-specific manner.

A major challenge facing $\mathrm{PD}$ research is to understand the molecular nature of nigral DAergic neuron-specific vulnerability. Using pHluorin live imaging for tracking SV dynamics at the nerve terminal, our study shows the differential effect of $L R R K 2$ G2019S in MB neurons (including DAergic neurons) compared with cortical neurons or hippocampal neurons in SV endocytosis. The lack of impaired SV endocytosis in cortical and hippocampal neurons expressing LRRK2-G2019S remains to be understood, and the downstream signaling mediating the slowed SV endocytosis in both $\mathrm{TH}^{+}$and $\mathrm{TH}^{-} \mathrm{MB}$ neurons in LRRK2 GStg mice needs to be characterized. Application of a LRRK2 kinase inhibitor in our study, however, suggests a clue for LRRK2 activitymodified synj 1 function in altering SV trafficking, although our conclusion could be strengthened by using more specific and potent LRRK2 kinase inhibitors and phospho-specific antibodies for synj1. It has yet to be determined whether LRRK2 phosphorylation of synj1 impairs SV reavailability, and thereby reduces exocytosis when combining the mutations (Fig. 4). Recent search for LRRK2 targets has also identified several GTPase rab proteins as LRRK2 substrates (Steger et al., 2016). Although the role for rab proteins (e.g., rab10 and rab12) in SV trafficking has not been demonstrated, it remains possible that mutant LRRK2 targets multiple proteins that are involved in vesicular trafficking, and the effects could be due to the combination of several modified trafficking molecules during SV cycling. Alternatively, the brain region-specific availability of the different LRRK2 targets and LRRK2 kinase regulation are likely to influence the outcome of the altered SV trafficking. Although it is unclear whether reduced SYNJ1 expression (e.g., SYNJ1 ${ }^{+/-}$mice) drives DAergic neuron toxicity, a recent report by Cao et al. (2017) demonstrates that disease-related mutation of synj1 (with reduced SAC1-like phosphatase activity) leads to dystrophic axons selectively in DAergic neurons. Collectively, the existing evidence suggests that the dysfunctional SV endocytosis in the MB region may be crucial to the selective vulnerability of DAergic neuron.

Impaired SV trafficking has long been implicated in the pathogenic pathway of PD. Several PARK genes were previously 
shown to disrupt SV cycling. Mutations or altered expression of SNCA (Larsen et al., 2006; Nemani et al., 2010; Lundblad et al., 2012; Xu et al., 2016) and DNAJC6 (Yim et al., 2010; Edvardson et al., 2012) have been shown to deregulate SV exocytosis and endocytosis. DNAJC6 encodes auxilin-1, which is a direct partner of synj1 in clathrin coat removal. Interestingly, mutations in both genes lead to early-onset Parkinsonism with epilepsy. Another close partner of synj1, endoA, was also known as a substrate of LRRK2 kinase. Phosphorylation of endoA impairs endocytic kinetics in Drosophila NMJ (Matta et al., 2012). Although it is unclear whether endoA phosphorylation disrupts its interaction with synj1, our biochemical study suggests that the phosphorylation of synj1 by LRRK2 impairs endoA-synj1 interaction. It is likely that synj1 and endoA are both targets of hyperactive LRRK2 mutant kinase, which deregulates the endoA-synj 1 complex in endocytosis and contributes to nerve terminal dysfunction and neuronal vulnerability (Cao et al., 2017). Our study shows that animals carrying both LRRK2 G2019S mutation and SYNJ1 ${ }^{+/-}$ display behavioral deficits in specific motor function tests, consistent with the idea that the two mutants genetically interact with each other perhaps at multiple pathways and in multiple brain regions, by which the combining effects facilitate the disease onset.

In conclusion, our study shows that multiple PD-related mutants disrupt SV trafficking in brain regions that are highly relevant to PD pathogenesis. LRRK2 and SYNJ1 may share the same pathogenic pathway at nerve terminals, which involves aberrant LRRK2 kinase activity and impairment of DA transmission as an early pathological event of PD.

\section{References}

Ariel P, Ryan TA (2010) Optical mapping of release properties in synapses. Front Neural Circuits 4:18. CrossRef Medline

Arranz AM, Delbroek L, Van Kolen K, Guimarães MR, Mandemakers W, Daneels G, Matta S, Calafate S, Shaban H, Baatsen P, De Bock PJ, Gevaert K, Vanden Berghe P, Verstreken P, De Strooper B, Moechars D (2015) LRRK2 functions in synaptic vesicle endocytosis through a kinasedependent mechanism. J Cell Sci 128:541-552. CrossRef Medline

Beccano-Kelly DA, Kuhlmann N, Tatarnikov I, Volta M, Munsie LN, Chou P, Cao LP, Han H, Tapia L, Farrer MJ, Milnerwood AJ (2014) Synaptic function is modulated by LRRK2 and glutamate release is increased in cortical neurons of G2019S LRRK2 knock-in mice. Front Cell Neurosci 8:301. CrossRef Medline

Beccano-Kelly DA, Volta M, Munsie LN, Paschall SA, Tatarnikov I, Co K, Chou P, Cao LP, Bergeron S, Mitchell E, Han H, Melrose HL, Tapia L, Raymond LA, Farrer MJ, Milnerwood AJ (2015) LRRK2 overexpression alters glutamatergic presynaptic plasticity, striatal dopamine tone, postsynaptic signal transduction, motor activity and memory. Hum Mol Genet 24:1336-1349. CrossRef Medline

Belluzzi E, Gonnelli A, Cirnaru MD, Marte A, Plotegher N, Russo I, Civiero L, Cogo S, Carrion MP, Franchin C, Arrigoni G, Beltramini M, Bubacco L, Onofri F, Piccoli G, Greggio E (2016) LRRK2 phosphorylates presynaptic N-ethylmaleimide sensitive fusion (NSF) protein enhancing its ATPase activity and SNARE complex disassembling rate. Mol Neurodegener 11:1. CrossRef Medline

Cao M, Wu Y, Ashrafi G, McCartney AJ, Wheeler H, Bushong EA, Boassa D, Ellisman MH, Ryan TA, De Camilli P (2017) Parkinson sac domain mutation in synaptojanin 1 impairs clathrin uncoating at synapses and triggers dystrophic changes in dopaminergic axons. Neuron 93:882-896.e5. CrossRef Medline

Cestra G, Castagnoli L, Dente L, Minenkova O, Petrelli A, Migone N, Hoffmüller U, Schneider-Mergener J, Cesareni G (1999) The SH3 domains of endophilin and amphiphysin bind to the proline-rich region of synaptojanin 1 at distinct sites that display an unconventional binding specificity. J Biol Chem 274:32001-32007. CrossRef Medline

Chang-Ileto B, Frere SG, Chan RB, Voronov SV, Roux A, Di Paolo G (2011) Synaptojanin 1-mediated PI $(4,5) \mathrm{P} 2$ hydrolysis is modulated by mem- brane curvature and facilitates membrane fission. Dev Cell 20:206-218. CrossRef Medline

Cremona O, Di Paolo G, Wenk MR, Lüthi A, Kim WT, Takei K, Daniell L, Nemoto Y, Shears SB, Flavell RA, McCormick DA, De Camilli P (1999) Essential role of phosphoinositide metabolism in synaptic vesicle recycling. Cell 99:179-188. CrossRef Medline

Di Paolo G, De Camilli P (2006) Phosphoinositides in cell regulation and membrane dynamics. Nature 443:651-657. CrossRef Medline

Dong Y, Gou Y, Li Y, Liu Y, Bai J (2015) Synaptojanin cooperates in vivo with endophilin through an unexpected mechanism. Elife 4:7554. CrossRef Medline

Edvardson S, Cinnamon Y, Ta-Shma A, Shaag A, Yim YI, Zenvirt S, Jalas C, Lesage S, Brice A, Taraboulos A, Kaestner KH, Greene LE, Elpeleg O (2012) A deleterious mutation in DNAJC6 encoding the neuronalspecific clathrin-uncoating co-chaperone auxilin, is associated with juvenile parkinsonism. PLoS One 7:e36458. CrossRef Medline

Fleming SM, Salcedo J, Fernagut PO, Rockenstein E, Masliah E, Levine MS, Chesselet MF (2004) Early and progressive sensorimotor anomalies in mice overexpressing wild-type human alpha-synuclein. J Neurosci 24: 9434-9440. CrossRef Medline

Guaitoli G, Raimondi F, Gilsbach BK, Gómez-Llorente Y, Deyaert E, Renzi F, Li X, Schaffner A, Jagtap PK, Boldt K, von Zweydorf F, Gotthardt K, Lorimer DD, Yue Z, Burgin A, Janjic N, Sattler M, Versées W, Ueffing M, Ubarretxena-Belandia I, et al. (2016) Structural model of the dimeric Parkinson's protein LRRK2 reveals a compact architecture involving distant interdomain contacts. Proc Natl Acad Sci U S A 113:E4357-E4366. CrossRef Medline

Hardy J, Cai H, Cookson MR, Gwinn-Hardy K, Singleton A (2006) Genetics of Parkinson's disease and parkinsonism. Ann Neurol 60:389-398. CrossRef Medline

Hernandez DG, Reed X, Singleton AB (2016) Genetics in Parkinson disease: Mendelian versus non-Mendelian inheritance. J Neurochem 139 [Suppl 1]: $59-74$.

Honigmann A, van den Bogaart G, Iraheta E, Risselada HJ, Milovanovic D, Mueller V, Müllar S, Diederichsen U, Fasshauer D, Grubmüller H, Hell SW, Eggeling C, Kühnel K, Jahn R (2013) Phosphatidylinositol 4,5bisphosphate clusters act as molecular beacons for vesicle recruitment. Nat Struct Mol Biol 20:679-686. CrossRef Medline

Islam MS, Nolte H, Jacob W, Ziegler AB, Pütz S, Grosjean Y, Szczepanowska K, Trifunovic A, Braun T, Heumann H, Heumann R, Hovemann B, Moore DJ, Krüger M (2016) Human R1441C LRRK2 regulates the synaptic vesicle proteome and phosphoproteome in a Drosophila model of Parkinson's disease. Hum Mol Genet 25:5365-5382. CrossRef Medline

Krebs CE, Karkheiran S, Powell JC, Cao M, Makarov V, Darvish H, Di Paolo G, Walker RH, Shahidi GA, Buxbaum JD, De Camilli P, Yue Z, PaisánRuiz C (2013) The Sac1 domain of SYNJ1 identified mutated in a family with early-onset progressive Parkinsonism with generalized seizures. Hum Mutat 34:1200-1207. CrossRef Medline

Larsen KE, Schmitz Y, Troyer MD, Mosharov E, Dietrich P, Quazi AZ, Savalle M, Nemani V, Chaudhry FA, Edwards RH, Stefanis L, Sulzer D (2006) Alpha-synuclein overexpression in PC12 and chromaffin cells impairs catecholamine release by interfering with a late step in exocytosis. J Neurosci 26:11915-11922. CrossRef Medline

Lee SY, Wenk MR, Kim Y, Nairn AC, De Camilli P (2004) Regulation of synaptojanin 1 by cyclin-dependent kinase 5 at synapses. Proc Natl Acad Sci U S A 101:546-551. CrossRef Medline

Li X, Patel JC, Wang J, Avshalumov MV, Nicholson C, Buxbaum JD, Elder GA, Rice ME, Yue Z (2010) Enhanced striatal dopamine transmission and motor performance with LRRK2 overexpression in mice is eliminated by familial Parkinson's disease mutation G2019S. J Neurosci 30:17881797. CrossRef Medline

Lundblad M, Decressac M, Mattsson B, Björklund A (2012) Impaired neurotransmission caused by overexpression of alpha-synuclein in nigral dopamine neurons. Proc Natl Acad Sci U S A 109:3213-3219. CrossRef Medline

Mani M, Ryan TA (2009) Live imaging of synaptic vesicle release and retrieval in dopaminergic neurons. Front Neural Circuits 3:3. CrossRef Medline

Mani M, Lee SY, Lucast L, Cremona O, Di Paolo G, De Camilli P, Ryan TA (2007) The dual phosphatase activity of synaptojanin1 is required for both efficient synaptic vesicle endocytosis and reavailability at nerve terminals. Neuron 56:1004-1018. CrossRef Medline

Matta S, Van Kolen K, da Cunha R, van den Bogaart G, Mandemakers W, 
Miskiewicz K, De Bock PJ, Morais VA, Vilain S, Haddad D, Delbroek L, Swerts J, Chávez-Gutiérrez L, Esposito G, Daneels G, Karran E, Holt M, Gevaert K, Moechars DW, De Strooper B, et al. (2012) LRRK2 controls an EndoA phosphorylation cycle in synaptic endocytosis. Neuron 75: 1008-1021. CrossRef Medline

Melrose HL, Dächsel JC, Behrouz B, Lincoln SJ, Yue M, Hinkle KM, Kent CB, Korvatska E, Taylor JP, Witten L, Liang YQ, Beevers JE, Boules M, Dugger BN, Serna VA, Gaukhman A, Yu X, Castanedes-Casey M, Braithwaite AT, Ogholikhan S, et al. (2010) Impaired dopaminergic neurotransmission and microtubule-associated protein tau alterations in human LRRK2 transgenic mice. Neurobiol Dis 40:503-517. CrossRef Medline

Nemani VM, Lu W, Berge V, Nakamura K, Onoa B, Lee MK, Chaudhry FA, Nicoll RA, Edwards RH (2010) Increased expression of alpha-synuclein reduces neurotransmitter release by inhibiting synaptic vesicle reclustering after endocytosis. Neuron 65:66-79. CrossRef Medline

Olgiati S, De Rosa A, Quadri M, Criscuolo C, Breedveld GJ, Picillo M, Pappatà S, Quarantelli M, Barone P, De Michele G, Bonifati V (2014) PARK20 caused by SYNJ1 homozygous Arg258Gln mutation in a new Italian family. Neurogenetics 15:83-188. CrossRef Medline

Paisán-Ruíz C, Jain S, Evans EW, Gilks WP, Simón J, van der Brug M, López de Munain A, Aparicio S, Gil AM, Khan N, Johnson J, Martinez JR, Nicholl D, Carrera IM, Pena AS, de Silva R, Lees A, Martí-Massó JF, Pérez-Tur J, Wood NW, et al. (2004) Cloning of the gene containing mutations that cause PARK8-linked Parkinson's disease. Neuron 44:595600. CrossRef Medline

Pan PY, Ryan TA (2012) Calbindin controls release probability in ventral tegmental area dopamine neurons. Nat Neurosci 15:813-815. CrossRef Medline

Piccoli G, Onofri F, Cirnaru MD, Kaiser CJ, Jagtap P, Kastenmüller A, Pischedda F, Marte A, von Zweydorf F, Vogt A, Giesert F, Pan L, Antonucci F, Kiel C, Zhang M, Weinkauf S, Sattler M, Sala C, Matteoli M, Ueffing M, et al. (2014) Leucine-rich repeat kinase 2 binds to neuronal vesicles through protein interactions mediated by its C-terminal WD40 domain. Mol Cell Biol 34:2147-2161. CrossRef Medline

Plowey ED, Johnson JW, Steer E, Zhu W, Eisenberg DA, Valentino NM, Liu YJ, Chu CT (2014) Mutant LRRK2 enhances glutamatergic synapse activity and evokes excitotoxic dendrite degeneration. Biochim Biophys Acta 1842:1596-1603. CrossRef Medline

Quadri M, Fang M, Picillo M, Olgiati S, Breedveld GJ, Graafland J, Wu B, Xu F, Erro R, Amboni M, Pappatà S, Quarantelli M, Annesi G, Quattrone A, Chien HF, Barbosa ER, Barbosa ER, Oostra BA, Barone P, Wang J, et al. (2013) Mutation in the SYNJ1 gene associated with autosomal recessive, early-onset Parkinsonism. Hum Mutat 34:1208-1215. CrossRef Medline

Raimondi A, Ferguson SM, Lou X, Armbruster M, Paradise S, Giovedi S, Messa M, Kono N, Takasaki J, Cappello V, O’Toole E, Ryan TA, De Camilli P (2011) Overlapping role of dynamin isoforms in synaptic vesicle endocytosis. Neuron 70:1100-1114. CrossRef Medline

Sankaranarayanan S, De Angelis D, Rothman JE, Ryan TA (2000) The use of pHluorins for optical measurements of presynaptic activity. Biophys J 79:2199-2208. CrossRef Medline

Schuske KR, Richmond JE, Matthies DS, Davis WS, Runz S, Rube DA, van der Bliek AM, Jorgensen EM (2003) Endophilin is required for synaptic vesicle endocytosis by localizing synaptojanin. Neuron 40:749-762. CrossRef Medline
Sheng Z, Zhang S, Bustos D, Kleinheinz T, Le Pichon CE, Dominguez SL, Solanoy HO, Drummond J, Zhang X, Ding X, Cai F, Song Q, Li X, Yue Z, van der Brug MP, Burdick DJ, Gunzner-Toste J, Chen H, Liu X, Estrada AA, Sweeney ZK, et al. (2012) Ser1292 autophosphorylation is an indicator of LRRK2 kinase activity and contributes to the cellular effects of PD mutations. Sci Transl Med 4:164ra161. CrossRef Medline

Shin N, Jeong H, Kwon J, Heo HY, Kwon JJ, Yun HJ, Kim CH, Han BS, Tong Y, Shen J, Hatano T, Hattori N, Kim KS, Chang S, Seol W (2008) LRRK2 regulates synaptic vesicle endocytosis. Exp Cell Res 314:2055-2065. CrossRef Medline

Steger M, Tonelli F, Ito G, Davies P, Trost M, Vetter M, Wachter S, Lorentzen E, Duddy G, Wilson S, Baptista MA, Fiske BK, Fell MJ, Morrow JA, Reith AD, Alessi DR, Mann M (2016) Phosphoproteomics reveals that Parkinson's disease kinase LRRK2 regulates a subset of Rab GTPases. Elife 5:e12813. CrossRef Medline

Tong Y, Pisani A, Martella G, Karouani M, Yamaguchi H, Pothos EN, Shen J (2009) R1441C mutation in LRRK2 impairs dopaminergic neurotransmission in mice. Proc Natl Acad Sci U S A 106:14622-14627. CrossRef Medline

Trinh J, Gustavsson EK, Vilariño-Güell C, Bortnick S, Latourelle J, McKenzie MB, Tu CS, Nosova E, Khinda J, Milnerwood A, Lesage S, Brice A, Tazir M, Aasly JO, Parkkinen L, Haytural H, Foroud T, Myers RH, Sassi SB, Hentati E, et al. (2016) DNM3 and genetic modifiers of age of onset in LRRK2 Gly2019Ser parkinsonism: a genome-wide linkage and association study. Lancet Neurol 15:1248-1256. CrossRef Medline

van den Bogaart G, Meyenberg K, Diederichsen U, Jahn R (2012) Phosphatidylinositol 4,5-bisphosphate increases $\mathrm{Ca}^{2+}$ affinity of synaptotagmin-1 by 40-fold. J Biol Chem 287:16447-16453. CrossRef Medline

Verstreken P, Koh TW, Schulze KL, Zhai RG, Hiesinger PR, Zhou Y, Mehta SQ, Cao Y, Roos J, Bellen HJ (2003) Synaptojanin is recruited by endophilin to promote synaptic vesicle uncoating. Neuron 40:733-748. CrossRef Medline

West AB, Moore DJ, Biskup S, Bugayenko A, Smith WW, Ross CA, Dawson VL, Dawson TM (2005) Parkinson's disease-associated mutations in leucine-rich repeat kinase 2 augment kinase activity. Proc Natl Acad Sci U S A 102:16842-16847. CrossRef Medline

Xu J, Wu XS, Sheng J, Zhang Z, Yue HY, Sun L, Sgobio C, Lin X, Peng S, Jin Y, Gan L, Cai H, Wu LG (2016) alpha-Synuclein mutation inhibits endocytosis at mammalian central nerve terminals. J Neurosci 36:4408-4414. CrossRef Medline

Yim YI, Sun T, Wu LG, Raimondi A, De Camilli P, Eisenberg E, Greene LE (2010) Endocytosis and clathrin-uncoating defects at synapses of auxilin knockout mice. Proc Natl Acad Sci U S A 107:4412-4417. CrossRef Medline

Yue Z, Lachenmayer ML (2011) Genetic LRRK2 models of Parkinson's disease: dissecting the pathogenic pathway and exploring clinical applications. Mov Disord 26:1386-1397. CrossRef Medline

Zimprich A, Biskup S, Leitner P, Lichtner P, Farrer M, Lincoln S, Kachergus J, Hulihan M, Uitti RJ, Calne DB, Stoessl AJ, Pfeiffer RF, Patenge N, Carbajal IC, Vieregge P, Asmus F, Müller-Myhsok B, Dickson DW, Meitinger T, Strom TM, et al. (2004) Mutations in LRRK2 cause autosomal-dominant parkinsonism with pleomorphic pathology. Neuron 44:601-607. CrossRef Medline 